\title{
The Effect of Stress on Compulsive Sexual Behavior Disorder: Active Coping Strategy and Self-Control as Mediators
}

Jae Woo Park ${ }^{*}$, Dai Jin Kim, and Mi Hyun Shin ${ }^{\bowtie}$

Department of Counseling Psychology, Korea Counseling Graduate University, Seoul, Republic of Korea

Psychiatry Investig 2021;18(10):997-1005

https://doi.org/10.30773/pi.2021.0010

Unfortunately, the author's affiliation was incorrect in the original publication of this article. The correct affiliation is given below.

Jae Woo Park', Dai Jin Kim², and Mi Hyun Shin ${ }^{1}$

${ }^{1}$ Department of Counseling Psychology, Korea Counseling Graduate University, Seoul, Republic of Korea

${ }^{2}$ Department of Psychiatry, Seoul St. Mary's Hospital, College of Medicine, Catholic University of Korea, Seoul, Republic of Korea

(a) This is an Open Access article distributed under the terms of the Creative Commons

Attribution Non-Commercial License (http://creativecommons.org/licenses/by-

nc/4.0) which permits unrestricted non-commercial use, distribution, and reproduc-

tion in any medium, provided the original work is properly cited. 